University of Nebraska - Lincoln

DigitalCommons@University of Nebraska - Lincoln

April 1978

\title{
Microhabitat Selection in Two Species of Heteromyid Rodents
}

Cliff A. Lemen

University of Nebraska-Lincoln, clemen2@unl.edu

Michael L. Rosenzweig

University of Arizona

Follow this and additional works at: https://digitalcommons.unl.edu/natrespapers

Part of the Natural Resources and Conservation Commons

Lemen, Cliff A. and Rosenzweig, Michael L., "Microhabitat Selection in Two Species of Heteromyid Rodents" (1978). Papers in Natural Resources. 29.

https://digitalcommons.unl.edu/natrespapers/29

This Article is brought to you for free and open access by the Natural Resources, School of at DigitalCommons@University of Nebraska - Lincoln. It has been accepted for inclusion in Papers in Natural Resources by an authorized administrator of DigitalCommons@University of Nebraska - Lincoln. 


\title{
Microhabitat Selection in Two Species of Heteromyid Rodents
}

\author{
Cliff A. Lemen ${ }^{1}$ and Michael L. Rosenzweig ${ }^{2}$ \\ ${ }^{1}$ Biology Department, University of New Mexico, Albuquerque, NM 87131, USA \\ ${ }^{2}$ Department of Ecology and Evolutionary Biology, University of Arizona, Tucson, AZ 85721, \\ USA
}

Summary. An experiment was conducted to determine the microhabitat preferences of two heteromyid rodents, Dipodomys ordi and Perognathus flavus. This experiment used marked seeds and the atomic absorption spectrophotometer in order to study the environment as a mosaic of microhabitats. The results of our analysis indicate that these two heteromyids are microhabitat selectors. The preferences of the rodents are, $D$. ordi: grass habitat $0.0 \%$, near grass habitat $22.5 \%$, open habitat $77.4 \%$, and P. flavus: grass habitat $46.2 \%$, near grass habitat $32.2 \%$, open habitat $21.4 \%$. The overlap between the two species is only 0.43 .

\section{Introduction}

Communities of rodents in the family Heteromyidae can have high species diversity; localities with six or seven species are not uncommon (Brown, 1975). This high community diversity is interesting since superficially most heteromyids have similar ecologies; they are largely granivorous, burrowing, and nocturnal.

Two mechanisms of niche separation have been suggested in heteromyids. They are habitat selection (Rosenzweig, 1973; Brown, 1975) and seed size allocation (Brown and Lieberman, 1973; Brown, 1975; Smigel and Rosenzweig, 1974; Lemen, in prep.). In the present study I investigate the microhabitat selectivity of two heteromyids, Dipodomys ordi and Perognathus flavus, in a desert grassland of central New Mexico.

This pair of rodents is particularly interesting for two reasons. First, their body sizes are extremely different, $D$. ordi in this part of its range weigh about $48 \mathrm{~g}$, whereas $P$. flavus weighs at most $8 \mathrm{~g}$. This places the two species almost at opposite extremes of weight in the scale of Brown (1975), and makes it possible to predict from that work a likelihood these two species are resource allocating on the basis of seed size. 
Second, the two species inhabit an arid grassland where the vegetational physiognomy is relatively simple. Based on Rosenzweig, Smigel and Kraft (1975), one is led to predict from such simplicity that habitat selection is not as probable as it might be in a more shrubby environment.

In most previous habitat selection studies on rodents (Brown, 1975; Rosenzweig, 1973) trapping was used to determine microhabitat preferences. Traps were placed in different microhabitats and trap success would indicate a species selectivity. This method is simple and inexpensive, but it suffers from some drawbacks. One is that the presence of a trap alters a microhabitat. Thus, whether a trap is crushing down grass or offering protective cover on an otherwise bare patch of ground, it modifies the local environment. As Rosenzweig (1973) demonstrated, structural changes in the habitat can result in spatial shifts in rodents' usage of an area.

A second problem is that trapping discovers only where the animal was. It does not tell what the rodent was doing in that microhabitat before it was caught. The mouse may have been foraging or simply passing through a habitat when it came upon the trap.

In an attempt to avoid both these problems and others, we developed a new technique to determine habitat selectivity. This technique is a modification of one used by Smigel and Rosenzweig (1974) in a seed selection experiment. In our experiments, seeds marked with environmentally rare elements are spread in different microhabitats. One marker element is assigned to each microhabitat type. As the rodents forage, they encounter marked seed types in proportion to their use of the microhabitats. Later, the rodents are trapped and fecal samples are taken for analysis with an atomic absorption spectrophotometer. With this method no modification of the structure of the habitat is needed, and actual foraging activity determines the rodents' indicated use of the patches of habitat.

\section{The Site}

This study was conducted between June 1973 and August 1975, 19 Km east of San Antonio, New Mexico in a desert grassland belonging to the U. S. Bureau of Land Management. The study area is within a broad shallow basin (the northern edge of the Jornada del Muerto) which is bounded on the north, east, and west by low rocky hills. This basin is at about $1580 \mathrm{~m}$ elevation and receives on the average $22.3 \mathrm{~cm}$ of precipitation per year (Socorro, N.M. weather station). The basin's floor is covered by an arid grassland. Although this area is grazed by cattle, it still contains sections with excellent stands of grass. Typically, the patches of grass may be up to a few meters wide interspaced with bare ground of about the same size. In the sites we chose for this microhabitat selection study, the stands of grass were excellent, dense and full, and the grass often was standing $0.6 \mathrm{~m}$ high.

Dominant plants of the grassland association include: Salsola kali, Hilaria sp., Sporobolus cryptandrus, Aristida divaricata, Phacelia sp., Euphorbia spp., Gutierrezia saothrae, Schleropogon brevifolius, Tridens pulchellus, Mentzelia pumila, and somewhat spotty in distribution, Yucca glauca and Prosopis juliflora.

As the basin slopes up to the low hills, there is a sharp transition from the grassland to a creosote (Larrea tridentata) association. In these areas the ground becomes a desert pavement and plant cover is sparse. Other dominant plants of this habitat are Eriogonum sp. and Muhlenburgia sp. 
Although this study will focus on the actions of D. ordi and P. flavus in the grassland habitat, several other rodents were trapped in the area. They included: Spermophilus spilosoma, Perognathus flavescens, P. intermedius, Dipodomys merriami, D. spectabilis, Onychomys leucogaster, Neotoma albigula, Peromyscus eremicus, P. leucopus, Sigmodon hispidus, and Reithrodontomys sp.

Macrohabitat selection is very important in the ecology of the heteromyids of this area. Perognathus intermedius is found only on the rocky hillsides, D. merriami is always associated with the creosote stands, while $D$. ordi is caught almost exclusively in the grassy areas (Schroder and Rosenzweig, 1975). Only P. flavus and D. spectabilis occur in both the grassland and creosote communities. The last heteromyid, P. flavescens, was captured too rarely to get a clear picture of its habitat preferences. However, Williams (1968), mentions that this species probably macrohabitat selects with P. flavus, flavescens preferring the sandy habitats along dry washes.

Although 6 species of heteromyid rodents do occur within a kilometer of the study sites, only 3 at a time can be found as truly syntopic. Thus, macrohabitat selection can account for much of the coexistence within this community.

\section{Methods}

Batches of millet seeds were tagged with different chemical markers in 1/40 molar solutions for $72 \mathrm{~h}$. The chemical markers were selected to be non-toxic and to contain an environmentally rare element which can be analyzed with an atomic absorption spectrophotometer. Three markers were chosen for this study: In $\mathrm{Cl}_{3}, \mathrm{Cr} \mathrm{Cl}_{2}$ and $\mathrm{Cd} \mathrm{Cl}_{2}$. Although three markers were sufficient for this study, more elemental markers exist that could serve in more complex studies. Each marker element was assigned a microhabitat in which it was spread. For the purpose of this experiment, the grassland habitat was considered to be a mosaic of three microhabitats: the grass microhabitat (In), defined as patches which supported grass stands; the near grass microhabitat (Cr), defined as bare ground within $1 / 3 \mathrm{~m}$ of the grass microhabitat; and the open microhabitat $(\mathrm{Cd})$, defined as bare ground areas more than $1 / 3 \mathrm{~m}$ away from the grass.

On the experimental plots seeds of each marker were spread in their assigned microhabitats at the density of $5 \mathrm{~g} / \mathrm{m}^{2} /$ day for a total of $4 \mathrm{~m}^{2}$ per marker. The plots were carefully picked to have a sufficient area so that the three microhabitats could be contiguous. This seeding procedure was repeated for three evenings; seeding was always done in the evening to minimize the effect of diurnal seed predators, such as ants and birds.

The seeding was repeated for three days for two reasons. First, Smigel et al. (1974) found that the marker elements came to equilibrium in the rodents feces after three days of exposure. Second, we hoped to maintain the relative densities of marked seeds at equal levels in each microhabitat. A difficulty in accomplishing this arises if one habitat is used more heavily than the others; competition for the marked millet seeds would become more intense in that habitat. After a time, because of high foraging rates, lower densities of marked seeds would exist in the preferred habitat. At that point rodents foraging there would receive fewer marked millet seeds per unit effort than they would in the less used habitats. By replenishing seeds every evening we hoped to maintain the seed densities approximately equal in all microhabitats. This problem will be discussed more fully in a later section.

After the 3rd day of seeding, each plot was trapped for two nights with clean Sherman live traps. Fecal samples were collected from the captive rodents and then they were released. These fecal samples were dry ashed at $550^{\circ} \mathrm{C}$, then steam-heated in a $4 \mathrm{~N}$ solution of $\mathrm{HCl}$. Samples were analyzed on a Beckman Atomic Absorption Spectrophotometer for the marker elements.

In order to estimate any differences between markers in their palatability or in their ability to be passed in the feces, control plots were also run. These were handled exactly as the experimentals except that seeds with each marker were spread in all three microhabitats. Therefore, any differences in the concentrations of the markers in feces of control rodents must have been due to all factors other than habitat selection. 
Two more types of controls were also run. They were background and contamination controls. On the background plots, unmarked millet seeds were spread to check for possible background levels of the marker elements in the millet seed or environment. On contamination plots, seeds of one marker element were spread equally on all microhabitats. Contamination plots were run for each of the three chemical markers to check for possible cross contamination between the chemicals during the preparation of marked seed in the laboratory. Both of these controls yielded negative results; background and contamination were both below the detection sensitivity of our methods.

A total of four types of plots were set out, experimental plots and three kinds of control plots. Plots of the same kind were set out over the study area at $25 \mathrm{~m}$ intervals. Plots of different types were separated by at least $300 \mathrm{~m}$.

\section{Results}

The physiology-palatability controls reveal considerable deviation from the null hypothesis frequencies of $0.333,0.333$, and 0.333 (Table 1). Since there is no significant difference between the deviations found for $P$. flavus compared to those of $D$. ordi, control data for these two species are combined. In order to adjust for the effects of physiological or palatability differences among the elemental markers correction factors are needed. The correction factors are calculated in the following manner (as demonstrated for the In correction factor):

$$
\frac{\sum_{i=1}^{N} \frac{C f_{I n}\left(\text { Control } I n_{i}\right)}{C f_{I n}\left(\text { Control } I n_{i}\right)+C f_{C r}\left(\text { Control } C r_{i}\right)+C f_{C d}\left(\text { Control } C d_{i}\right)} 100}{N}=33.3 \% \text {. }
$$

Where $N$ is equal to the number of animals in the control data set; Control $\operatorname{In}_{i}$, Control $\mathrm{Cr}_{i}$, and Control $\mathrm{Cd}_{i}$ are the concentrations of $\mathrm{In}, \mathrm{Cr}$, and $\mathrm{Cd}$ respectively found in the feces of the $i$ th control animal; and $C f_{I n}, C f_{C r}$, and $C f_{C d}$ are the correction factors. As can be seen, only the relative size of the correction factors is important. Thus $C f_{C d}$ is set equal to 1.0 and the other correction factors solved so that all corrected control percentages are equal to $33.3 \%$ simultaneously. The corrected experimental percentages are calculated from the above formula using the correction factors just generated. The corrected experimental percentages

Table 1. The control and experimental data for the three marker experiment. The percentages with asterisks are significantly different from the control data ( $P=0.05$ using the Mann-Whitney U test).

\begin{tabular}{llccc}
\hline Controls & & In & $C r$ & $C d$ \\
\hline$P$. flavus and D. ordi & Concentrations (ppm) & 9.8 & 7.9 & 21.4 \\
$n=22$ & Raw percent & $25.0 \%$ & $20.2 \%$ & $54.8 \%$ \\
& Correction factor & 2.95 & 4.57 & 1.00 \\
& Corrected percent & 33.3 & 33.3 & 33.3 \\
\hline Experimentals & & grass & near-grass & open \\
& & $($ In $)$ & $($ Cr $)$ & $($ Cd $)$ \\
\hline$P$. flavus & Concentrations (ppm) & 19.3 & 7.6 & 19.6 \\
$n=41$ & Corrected percent & $46.2 \% *$ & $32.3 \%$ & $21.4 \% *$ \\
$D$. ordi & Concentrations (ppm) & 0.3 & 15.4 & 74.6 \\
$n=8$ & Corrected percentage & $0.0 \% *$ & $22.5 \% *$ & $77.4 \% *$ \\
\hline
\end{tabular}


appear in Table 1. By correcting the experimental data in this fashion, we allow only differences due to habitat selection to remain in the corrected percentages.

The most striking result in Table 1 is the excellent niche separation between $D$. ordi and P. flavus. This may be quantified by calculating an overlap for this data using the Schoener (1968) method:

$$
\alpha=1-\frac{1}{2} \sum_{i=1}^{n}\left|p_{1, i}-p_{2, i}\right|
$$

where $p_{1, i}$ is the proportion of utilization of the $i$ th resource state by the first species. The overlap value in this case is 0.43 . An exact quantification of the importance of this overlap is difficult to assess as this overlap value cannot be equated to a Lotka-Volterra competitive alpha. Qualitatively, however, this one axis appears to yield good niche separation, perhaps enough to explain the coexistence of these two species. Indeed, seed size allocation, supposedly another axis of niche separation, proves unimportant in ecologically separating these two species (Lemen, in prep.).

The excellent separation in habitat use is due largely to $D$. ordi's unwillingness to use the grass habitat. This preference is not surprising; the dense grass is a complex maze of roots and stems where the large and bipedal $D$. ordi would be unable to maneuver efficiently. It, is also interesting, however, that the small pocket mouse, while foraging everywhere, does prefer the dense grassy habitat (46\%). This preference may be related to increased protection against predators due to the grass cover. How accurate are these results? To find this, the percent usage of each microhabitat for all 41 experimental P. flavus are plotted in histograms (Fig. 1).

These histograms indicate there is a great deal of variability in the data. Also, it is obvious that the data are non-normal. Even the standard sorts of transformations fail to yield normal distributions from these data. Naturally, without normality it is not possible to calculate the standard errors and generate confidence limits. However, a cruder method may be used to calculate confidence limits if we assume that these data reasonably represent the distribution of results obtainable from this experiment.

Instead of using the assumption of a normal distribution to generate a standard error, it is possible to accept the actual frequency distribution of the experimental data as the distribution from which to estimate confidence limits. This is simple with a computer.

The data from those original $41 \mathrm{P}$. flavus are turned into a source pool. From this pool 1000 subsamples of 41 individuals each are taken (sampling with replacement). The means for these 1000 subsamples were calculated and are graphed in Figure 2. These histograms give a new view of the data, and are much more normal. Standard deviations can be calculated from these data, and will be estimators of the standard errors of the experimental data. The standard errors averaged 4.3 for the three microhabitats, and the 0.5 confidence limits are $\pm 8.7 \%$.Confidence limits generated from the $D$. ordi data are slightly smaller than those found from P. flavus. 

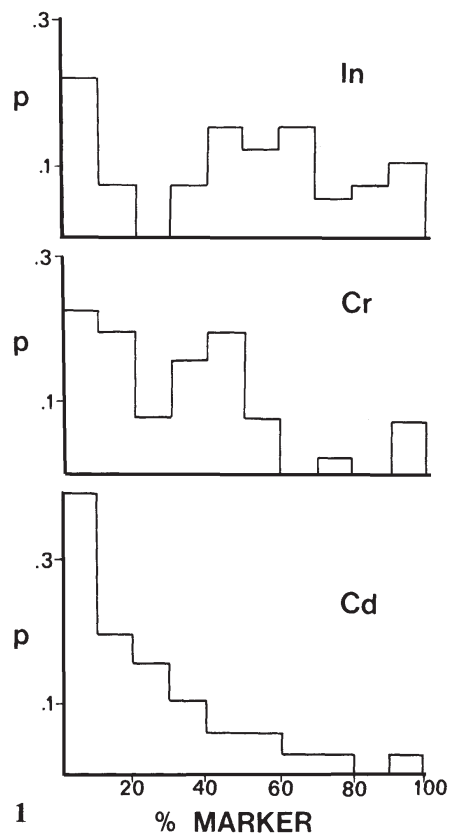
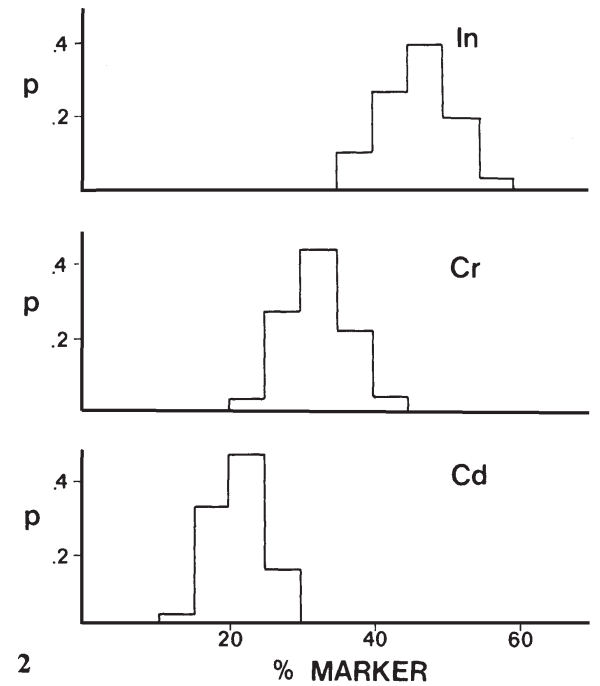

Fig. 1. The experimental data for 41 P. flavus are plotted in histograms to show the variability of the data. The plots represent the proportion of animals with various percentages of elemental marker in their feces.

Fig. 2. These are the calculated distributions of computer subsamples for the original P. flavus data.

A test of the repeatability of this experiment is also possible. Before the 3 marker experiment described above was performed, another independent experiment was made with only two microhabitats marked, grass (In) and open (Cd) (Table 2). These two experiments are absolutely independent. The areas used as controls and experimental plots were different, and the experiments were run a month apart. The marked seeds were made up in separate batches, and the samples were ashed and run on the atomic absorption spectrophotometer on different days. The data was analyzed as described above, for the three marker case. For proper comparisons the three marker data already discussed is also re-calculated, this time considering only the percentages of two markers, In and Cd. The results are shown in Table 3. The agreement between the two studies is good, and within the error limits calculated above.

One problem mentioned in the introduction is competition for marked seeds. For instance, it could be argued that $D$. ordi with its high preference for open ground might reduce the concentration of seeds there to a much lower level than is present in the grass. This would make it more difficult for the $P$. flavus to find seeds in the open than in the grass, even if they spent equal time foraging in both habitats. Referring back to Table 1 we might ask this question: 
Table 2. Shown here are the control and experimental data for the two marker experiment. The percentages with asterisks are significantly different from the control data $(P=0.05$ using the Mann-Whitney U test).

\begin{tabular}{llll}
\hline Controls & & In & Cd \\
\hline P. flavus and D. ordi & Concentrations (ppm) & 19.2 & 23.9 \\
$n=15$ & Raw percent & 33.0 & 67.0 \\
& Correction factors & 2.07 & 1.0 \\
& Corrected percents & $50.0 \%$ & $50.0 \%$ \\
\hline Experimentals & & grass & open \\
& & $($ In $)$ & $($ Cd $)$ \\
\hline P. flavus & Concentration (ppm) & 51.7 & 44.1 \\
$n=23$ & Corrected percent & $66.7 \% *$ & $33.3 \% *$ \\
$D$. ordi & Concentrations (ppm) & 2.0 & 118.1 \\
$n=12$ & Corrected percent & $2.0 \% *$ & $98.0 \% *$ \\
\hline
\end{tabular}

\begin{tabular}{llrr}
\hline Species & & \multicolumn{1}{l}{$\begin{array}{l}\text { Grass } \\
(\text { In })\end{array}$} & \multicolumn{1}{c}{$\begin{array}{l}\text { Open } \\
(\text { Cd })\end{array}$} \\
\hline P. flavus & $(3)$ & $64.0 \%$ & $36.0 \%$ \\
P. flavus & $(2)$ & $67.0 \%$ & $33.0 \%$ \\
D. ordi & $(3)$ & $0.0 \%$ & $100.0 \%$ \\
D. ordi & $(2)$ & $2.0 \%$ & $98.0 \%$ \\
\hline
\end{tabular}

Table 3. Shown here are two separate runs; the (3) run is the three marker case now reanalyzed for the two marker situation. The (2) run is the experiment in which two microhabitats only were marked (the near grass habitat was avoided).

Table 4. The data collected on P. flavus is split into two parts, plots 1 and 3 where $D$. ordi were found and plot 2 where no $D$. ordi were caught.

\begin{tabular}{lllll}
\hline Plot & $\begin{array}{l}\text { Grass } \\
(I n)\end{array}$ & $\begin{array}{l}\text { Near grass } \\
(C r)\end{array}$ & $\begin{array}{l}\text { Open } \\
(C d)\end{array}$ & $n$ \\
\hline With D. ordi & $45 \%$ & $34 \%$ & $21 \%$ & 23 \\
Without D. ordi & $47 \%$ & $30 \%$ & $22 \%$ & 18 \\
\hline
\end{tabular}

Does the reduced use of open habitat by P. flavus reflect actual preferences in usage or increased competition for seeds in that open habitat with $D$. ordi? Fortunately, there is a natural experiment available to test this question.

The results of Table 1 are made up of data from three separate areas within a few miles of one another. Each area was picked to be structurally identical to the others. However, when area two was trapped, absolutely no $D$. ordi were caught, although $31 \mathrm{P}$. flavus were trapped. This is at great variance with the other areas where over $1 / 3$ of the rodents trapped were $D$. ordi. Such an occurrence is not uncommon. We have often found considerable variance in trap success in areas only a short distance apart, and seemingly identical. 
Whatever the cause, this variation does present some interesting possibilities. If the $D$. ordi were significantly reducing the concentration of seeds in the open habitat, absence of $D$. ordi from this plot should have increased the relative use of the open habitat by P. flavus. Table 4 shows the results of dividing the data into two parts, plot 2 without and plots 1 and 3 with $D$. ordi. There was no significant increase in the use of the open habitat by P. flavus. Thus, D. ordi was not directly preventing $P$. flavus from using the open habitat.

\section{Discussion}

Probably the most popular model of heteromyid community ecology today is the one outlined in Brown (1975). In it niche differences between heteromyids are ascribed to a combination of habitat selection and resource allocation by seed size. However, in other research Lemen (in prep.), seed size allocation is shown not to be a factor in heteromyid niche separation. This is particularly surprising in the case of P. flavus $(8 \mathrm{~g})$ and $D$. ordi $(50 \mathrm{~g})$ whose great difference in body size places them almost at opposite extremes of the size range of arid zone heteromyids.

Given that these two species are not seed size allocating, what is the basis for their habitat selection? The answer probably lies in one or both of two variables: predator avoidance and seed clump size.

The bipedal design of Dipodomys is an adaptation for moving over open ground where exposure to predators must be significant. Webster (1962) has proposed that the other extraordinary difference between Dipodomys and Perognathus - their highly inflated tympanic bullae — is related to sophisticated predator avoidance. On the other hand, the smaller more quadrupedal Perognathus can weave through dense vegetation.

Yet, if predator avoidance is the only explanation for their habitat selection, why did the $D$. ordi show a much reduced preference for the open habitat near the grass as compared to the open habitat more than $0.3 \mathrm{~m}$ away from the grass (Table 1)? The near grass habitat is just as devoid of obstructions to bipedal locomotion.

The answer may lie in the fact that open areas away from obstructions have clumped seed distributions; whereas, those closer to obstructions have more evenly distributed seeds (Reichman, 1976). If the K-rat's swiftness, bipedalism, and larger size is also related to an ability to exploit occasional dense seed clumps, then it might avoid habitats near obstructions because they do not contain its preferred resource.

The technique used to obtain the results of this paper is much more efficient than the previously used technique involving neutron activation analysis. The latter requires a nuclear reactor, is very costly in time and money, and is no more capable of quantifying the orders of magnitude seen in our samples than is the atomic absorption spectrophotometer. Since the latter equipment is fairly widespread in universities with commitment to scientific research, it is our hope that this revision 
in technique will help to expand the application of stable isotope, rare cation tracer methodology to an increasing number of ecological field experiments.

\section{Conclusions}

The habitat percentages of $D$. ordi and P. flavus were determined using a new method which employs marked seeds and AA spectrophotometry. The results of the analysis indicate that $D$. ordi and P. flavus have very different selectivity for microhabitats, with an overlap between them of only 0.43 . Dipodomys ordi (50 g) preferred the open habitats, while P. flavus $(8 \mathrm{~g})$ had a preference for the grassy habitats. This excellent separation in habitat use appears sufficient in itself to allow coexistence.

Acknowledgments. Special thanks to James Findley, David Ligon, and Clifford Crawford for their help in the preparation of this paper. This work was supported by a grant from the National Science Foundation (GB-34804).

\section{References}

Brown, J .H.: Geographical ecology of desert rodents. In: Ecology and evolution of communities (M.L. Cody, J.M. Diamond, eds.). Cambridge, Massachusetts: The Belknap Press of Harvard University Press 1975

Brown, J.H., Lieberman, G.A.: Resource utilization and coexistence of seed eating desert rodents in a sand-dune habitat. Ecology 54, 788-797 (1973)

Lemen, C.A.: Seed size selection in heteromyids, a second look. In preparation

Reichman, O.J. : Seed distributions and the effect of rodents on germination of desert annuals. US/IBP Research Memorandum (1976)

Rosenzweig, M.L.: Habitat selection experiments with a pair of coexisting heteromyid rodent species. Ecology 54, 111-117 (1973)

Rosenzweig, M.L., Smigel, B.W., Kraft, A.: Patterns of food, space, and diversity. In: Rodents in desert environments (I. Prakash, P.K. Gosh, eds.). The Hague: Junk 1975

Schoener, T. W.: The anolis lizards of Bimini: resource partitioning in a complex fauna. Ecology 49, 704-726 (1968)

Schroder, G.D., Rosenzweig, M.L.: Perturbation analysis of competition and overlap in habitat utilization between Dipodomys ordi and Dipodomys merriami. Oecologia (Berl) 19, 9-28 (1975)

Shaw, W.T.: The ability of the Giant Kangaroo Rat as a harvester and storer of seeds. J. Mammal. 15, 275-286 (1934)

Smigel, B.W., Jester, W., Blomgren, J., Prasad, K.N., Rosenzweig, M.L.: Dietary analysis in granivores through the use of competition and overlap in habitat utilization between Dipodomys ordi and D. merriami. Oecologia (Berl.) 19, 9-28 (1975)

Smigel, B. W., Rosenzweig, M.L.: Seed selection in Dipodomys merriami and Perognathus penicillatus. Ecology 55, 329-339 (1974)

Vorhies, C. T., Taylor, W.P.: Life history of the kangaroo rat Dipodomys spectabilis spectabilis. U.S.D.A. Bull. 1091 (1922) 